DOI: $10.2478 /$ ace-2013-0016

\title{
INFLUENCE OF F-T SYNTHETIC WAX ON ASPHALT CONCRETE PERMANENT DEFORMATION
}

\author{
M. IWAŃSKI ${ }^{1}$, G. MAZUREK ${ }^{2}$
}

\begin{abstract}
The paper presents the results of the study of the effect of a Fischer-Tropsch (F-T) synthetic wax on the resistance to permanent deformation of the AC $11 \mathrm{~S}$ asphalt concrete. The synthetic wax was dosed at $1.5 \%, 2.5 \%$ and $3.5 \%$ by weight of bitumen $35 / 50$. The compaction temperatures were $115^{\circ} \mathrm{C}, 130^{\circ} \mathrm{C}$ and $145^{\circ} \mathrm{C}$. The criteria adopted for measuring the resistance to permanent deformation included the following parameters: stiffness modulus at 2,10 and $20^{\circ} \mathrm{C}$, permanent deformation (RTS), fatigue life determined using the indirect tensile fatigue test (ITFT) and resistance to rutting (WTSAIR, PRDAIR). The test results confirmed the positive influence of F-T synthetic wax on enhancing the permanent deformation resistance of asphalt concrete placed at lower compaction temperatures compared to that of standard asphalt concrete compacted at $140^{\circ} \mathrm{C}$.
\end{abstract}

Keywords: asphalt concrete, F-T synthetic wax, permanent deformation, stiffness modulus, resistance to rutting, fatigue

\section{INTRODUCTION}

Permanent deformation (rutting) is one of the most dangerous types of damage to bitumen pavements [1]. Numerous tests performed to find the ways of limiting the occurrence of rutting have been focused on bitumen modification [2, 3]. One of the modifying additions to be used for that purpose is an F-T (Fischer Tropsch) synthetic $\operatorname{wax}[4,5]$.

The tests described in this paper were conducted on the AC $11 \mathrm{~S}$ bituminous mixture for pavements under traffic load category KR4, manufactured to WT 2 - 2010 technical requirements and PN EN 13108-1.

The aggregate composition included $55 \%$ of gabbro rock fraction. A dolomite mix $0 / 4$ and granite fractured sand were used to increase fraction contents. Bitumen 35/50 (5.2\%) was the binder. Optimal grading curve has been done by means of authorial computer programme using particle packing method [19].

1 Faculty of Civil Engineering and Architecture, Kielce University of Technology, Al. Tysiąclecia Państwa Polskiego 7, 25-314 Kielce, Poland, e-mail: iwanski@tu.kielce.pl

2 Faculty of Civil Engineering, and Architecture, Kielce University of Technology, Al. Tysiąclecia Państwa Polskiego 7, 25-314 Kielce, Poland, e-mail: gmazurek@tu.kielce.pl 
The objective of the tests was to evaluate the influence of the F-T synthetic wax on such parameters as asphalt concrete stiffness modulus at a temperature of $2^{\circ} \mathrm{C}, 10^{\circ} \mathrm{C}$ and $20^{\circ} \mathrm{C}$, permanent deformation (RTS), fatigue life determined using the ITFT method, and potential to rutting. The testing programme was the basis for the optimisation process and identification of asphalt concrete properties most advantageous in terms of F-T wax amount and compaction temperature.

The temperature range of the tests was set at $115^{\circ} \mathrm{C}$ to $145^{\circ} \mathrm{C}$ with a $15^{\circ} \mathrm{C}$ step change. As the lowest value in the temperature range denotes the initiation of F-T wax crystallization process in the bitumen, the resistance of the asphalt concrete against permanent deformation at low compaction temperatures had to be measured. The highest value in the temperature range, i.e., $145^{\circ} \mathrm{C}$ is the recommended compaction temperature for asphalt concrete with bitumen 35/50. The results of tests conducted on asphalt concrete with F-T wax at this temperature allow evaluation of the bitumen liquidation on compaction and on mechanical parameters of the asphalt concrete.

All the parameters of the asphalt concrete (dependent variables) were evaluated based on the 3 (compaction temperature levels) x 3 (levels of modification with the F-T wax) factorial composite design. The design of the experiment consisted of two factors:

- temperature of compaction (three levels: $115^{\circ} \mathrm{C}, 130^{\circ} \mathrm{C}, 145^{\circ} \mathrm{C}$ ),

- amount of the modifier, F-T wax (three levels $1.5 \%, 2.5 \%, 3.5 \%$ ).

To unify the character of the asphalt concrete changes, a second-degree polynomial was used [6]. The schematic of the design is presented in Figure 1.

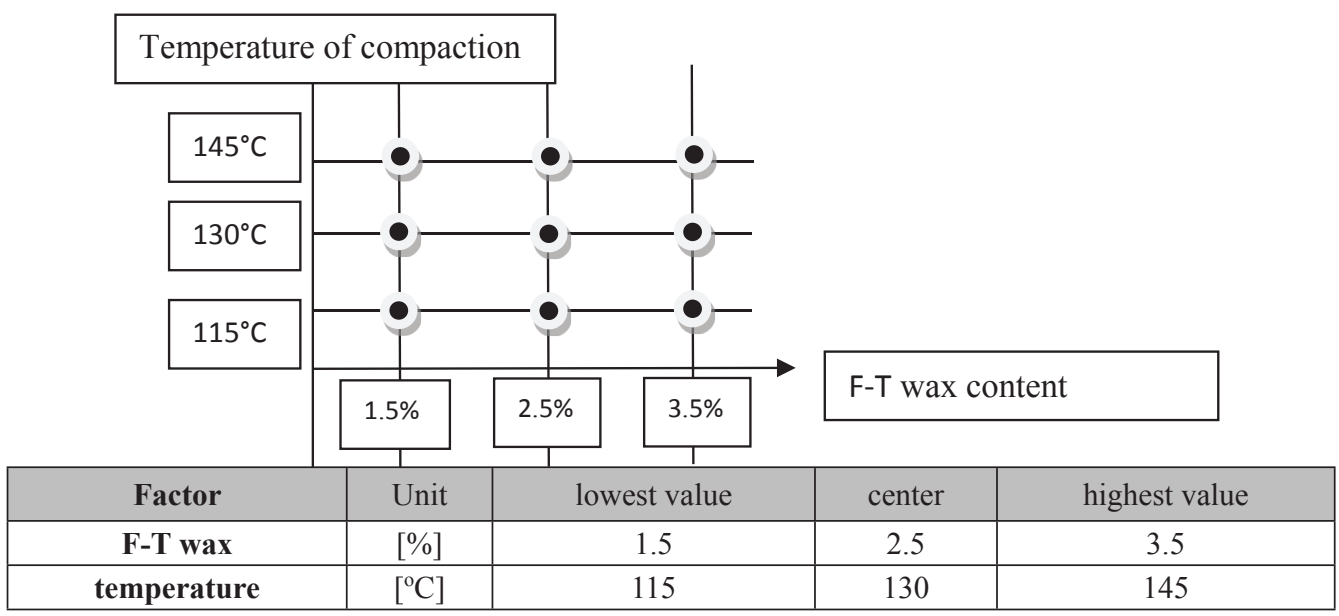

Fig. 1. Design of the experiment

The decision about such a design, with the characteristic densification of test points at the centre of the experiment domain was connected with the optimization study of 
F-T wax impact on rheological properties of bitumen, and resulted from the experience of similar analyses carried out for modifiers reducing the viscosity of bitumen $[7,8]$. The optimization results for the amount of modifier used in bitumen 35/50 indicated that the interval of $2.5 \%-3 \%$ was the best compromise between the increase in the F-T wax modified binder stiffness and its feasible increase in brittleness at low temperatures. Therefore, the design was strengthened with such modification variants.

\section{Asphalt Concrete stiffness modulus at temperatures of $2^{\circ} \mathrm{C}, 10^{\circ} \mathrm{C}$ and $20^{\circ} \mathrm{C}$}

The primary goal of the analysis of how the amount of the F-T synthetic wax and compaction temperature affect the changes in the stiffness modulus of $\mathrm{AC} 11 \mathrm{~S}$ at temperatures of $2^{\circ} \mathrm{C}, 10^{\circ} \mathrm{C}$ and $20^{\circ} \mathrm{C}(\mathrm{E} 2, \mathrm{E} 10$ and $\mathrm{E} 20)$ was to build a regression mathematical model (response surface). The domain of experiment determined the boundary conditions. The choice of the model to describe the variation of E2, E10 and E20 was the first step followed by the significance estimation of the fit parameters of the regression model.

The result of the goodness of fit of the model for the mechanical characteristics distribution of AC $11 \mathrm{~S}$ is presented in Table 1-4.

Table 1

Summarized statistics - goodness of fit tests of the AC $11 \mathrm{~S}$ with F-T wax model for E2, E10 and E20 (values of test temperature $2^{\circ} \mathrm{C}, 10^{\circ} \mathrm{C}, 20^{\circ} \mathrm{C}$ )

\begin{tabular}{|l|c|}
\hline Response Surface for Variable E2: E2 & 19346 \\
\hline Response Mean & 1031.946898 \\
\hline Root MSE & 0.76 \\
\hline R-Square & 5.3342 \\
\hline Coefficient of Variation & \\
\hline Response Surface for Variable E10: E10 & 13632 \\
\hline Response Mean & 1383.381567 \\
\hline Root MSE & 0.71 \\
\hline R-Square & 10.1477 \\
\hline Coefficient of Variation & \\
\hline Response Surface for Variable E20: E20 & 8011.520833 \\
\hline Response Mean & 564.453897 \\
\hline Root MSE & 0.77 \\
\hline R-Square & 7.0455 \\
\hline Coefficient of Variation & \\
\hline
\end{tabular}


Table 2

Detailed results of polynomial degree fit of the AC $11 \mathrm{~S}$ with F-T wax mathematical model for E2 (test temperature $2^{\circ} \mathrm{C}$ )

\begin{tabular}{|l|c|c|c|c|}
\hline \multicolumn{1}{|c|}{ Regression } & Type I Sum of Squares & R-Square & F-Value & Pr $>$ F \\
\hline Linear & 24960717 & 0.5471 & 11.72 & 0.0024 \\
\hline Quadratic & 7113636 & 0.2159 & 3.34 & 0.0474 \\
\hline Crossproduct & 2896222 & 0.0135 & 2.72 & 0.1301 \\
\hline Total Model & 34970574 & 0.776 & 6.57 & 0.0059 \\
\hline
\end{tabular}

Table 3

Detailed results of polynomial degree fit of the AC $11 \mathrm{~S}$ with F-T wax mathematical model for E10 (test temperature $10^{\circ} \mathrm{C}$ )

\begin{tabular}{|l|c|c|c|c|}
\hline \multicolumn{1}{|c|}{ Regression } & Type I Sum of Squares & R-Square & F-Value & Pr $>$ F \\
\hline Linear & 39274368 & 0.5844 & 10.26 & 0.0038 \\
\hline Quadratic & 6875930 & 0.1309 & 1.80 & 0.0515 \\
\hline Total Model & 48072097 & 0.7153 & 5.02 & 0.0146 \\
\hline
\end{tabular}

Table 4

Detailed results of polynomial degree fit of the AC $11 \mathrm{~S}$ with F-T wax mathematical model for E20 (measurement temperature $20^{\circ} \mathrm{C}$ )

\begin{tabular}{|l|c|c|c|c|}
\hline \multicolumn{1}{|c|}{ Regression } & Type I Sum of Squares & R-Squares & F-Value & Pr > F \\
\hline Linear & 14275042 & 0.6662 & 22.40 & 0.0002 \\
\hline Quadratic & 1993355 & 0.0930 & 3.13 & 0.0881 \\
\hline Crossproduct & 1974006 & 0.0921 & 6.20 & 0.0320 \\
\hline Total Model & 18242403 & 0.8513 & 11.45 & 0.0007 \\
\hline
\end{tabular}

The results of the analysis indicate that the square function model was the best fit for the AC $11 \mathrm{~S}$ stiffness modulus characteristic, regardless of the test temperature. The correlation coefficient took a range of values from 0.71-0.77. This means that the character of changes of the AC $11 \mathrm{~S}$ stiffness modulus of elasticity was assigned in a similar manner.

Figure 2 presents a graphical interpretation of the response surface of stiffness modulus variation for $\mathrm{E} 2$ (test temperature $2^{\circ} \mathrm{C}$ ) of the asphalt concrete in relation to the amount of F-T synthetic wax (L_V, \%) and temperature of compaction (TEMP, $\left.{ }^{\circ} \mathrm{C}\right)$. The results of the fit parameters estimation for the developed model are presented in Table 5. 


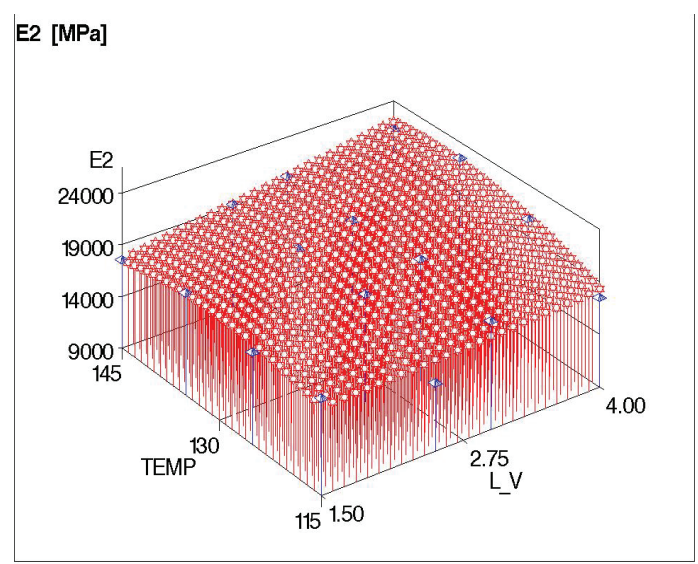

Fig. 2. The effect of the F-T wax (L_V) and the temperature of compaction (TEMP) on the response surface for $\mathrm{E} 2[\mathrm{MPa}]$ of $\mathrm{AC} 11 \mathrm{~S}$

Table 5

The results of the model parameters fit estimation (L_V and TEMP) for E2 of AC $11 \mathrm{~S}$ and the evaluation of their significance

\begin{tabular}{|l|c|c|c|c|}
\hline \multicolumn{1}{|c|}{ Parameter } & Estimation & Standard Error & Value of t & $\operatorname{Pr}>|\mathbf{t}|$ \\
\hline Intercept & -88258 & 44404 & -1.99 & 0.0749 \\
\hline TEMP & 1678.256090 & 674.844233 & 2.49 & 0.0322 \\
\hline L_V & -4773.629701 & 3838.791720 & -1.24 & 0.2420 \\
\hline TEMP*TEMP & -6.645625 & 2.579867 & -2.58 & 0.0276 \\
\hline L_V*TEMP & 42.217179 & 25.599452 & 1.65 & 0.1301 \\
\hline L_V*L_V & 72.527778 & 343.982299 & 0.21 & 0.8372 \\
\hline
\end{tabular}

The results of the analysis confirm a significant impact of the compaction temperature factor (TEMP) and its non-linear course on the stiffness modulus of the asphalt concrete for E2. The variance analysis did not indicate a significant influence of the F-T wax amount on the stiffness modulus of elasticity. Then, the temperature of compaction factor will affect the behaviour of AC $11 \mathrm{~S}$ asphalt concrete. As for the presence of the F-T synthetic wax, the concentration level of other crystals did not significantly increase the stiffness of the asphalt concrete, which positively affects its resistance to thermally induced cracking.

Figure 3 presents the graphical interpretation of the response surface of changes in the stiffness modulus E10 (test temperature $10^{\circ} \mathrm{C}$ ) of $\mathrm{AC} 11 \mathrm{~S}$ against the amount of the F-T synthetic wax (L_V, \%) and the compaction temperature (TEMP, $\left.{ }^{\circ} \mathrm{C}\right)$. The estimation results for the fit parameters for the developed model are presented in Table 6. 


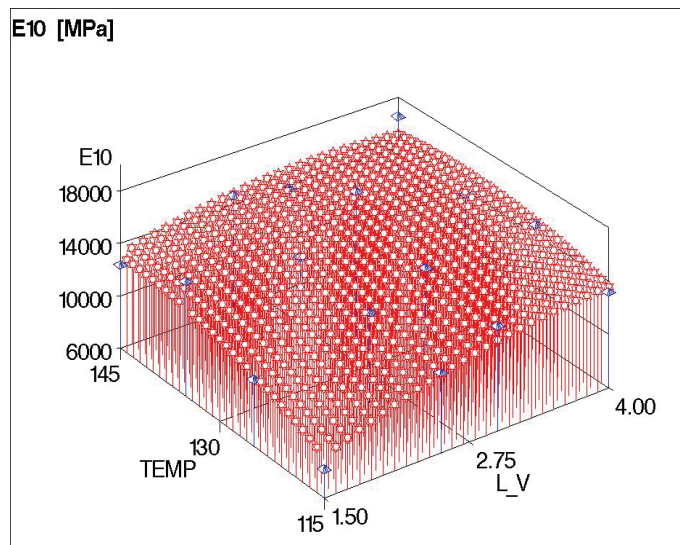

Fig. 3. The effect of the F-T wax amount (L_V) and the compaction temperature (TEMP) on the response surface for E10 [MPa] of AC $11 \mathrm{~S}$

Table 6

The estimation results of model (L_V and TEMP) parameters for characteristic E10 of AC $11 \mathrm{~S}$ and the estimation of their significance

\begin{tabular}{|l|c|c|c|c|}
\hline \multicolumn{1}{|c|}{ Parameter } & Estimation & Standard Error & Value of t & Pr $>|\mathbf{t}|$ \\
\hline Intercept & 64.111828 & 28.180866 & 2.28 & 0.0462 \\
\hline TEMP & -88258 & 44404 & -1.99 & 0.0749 \\
\hline L_V & 1678.256090 & 674.844233 & 2.49 & 0.0322 \\
\hline TEMP*TEMP & -4773.629701 & 3838.791720 & -1.24 & 0.2420 \\
\hline L_V*TEMP & -6.645625 & 2.579867 & -2.58 & 0.0276 \\
\hline L_V*L_V & 42.217179 & 25.599452 & 1.65 & 0.1301 \\
\hline
\end{tabular}

The results of the analysis indicate a relatively significant effect of the linear course of the compaction temperature (TEMP) and a highly significant effect of the F-T synthetic wax amount $\left(\mathrm{L}_{-} \mathrm{V}\right)$ on the stiffness modulus of $\mathrm{AC} 11 \mathrm{~S}$ at a temperature of $10^{\circ} \mathrm{C}$. Additionally, the effect of interaction between those two parameters emerged. Thus, at the temperature of $10^{\circ} \mathrm{C}$, the properties of asphalt concrete will also depend on the magnitude of void space compression (as at the temperature of $2^{\circ} \mathrm{C}$ ). There is, then, the effect of synergy of the F-T wax crystalline phase level and the temperature of compaction, which affect the stiffness modulus of $\mathrm{AC} 11 \mathrm{~S}$ at the temperature of $10^{\circ} \mathrm{C}$.

Figure 4 presents a graphical interpretation of the response surface of changes in the stiffness modulus E20 (test temperature $20^{\circ} \mathrm{C}$ ) of AC 11 S against the amount of the F-T synthetic wax (L_V, \%) and the compaction temperature (TEMP, $\left.{ }^{\circ} \mathrm{C}\right)$. The estimation results for the fit parameters for the developed model are presented in Table 7. 


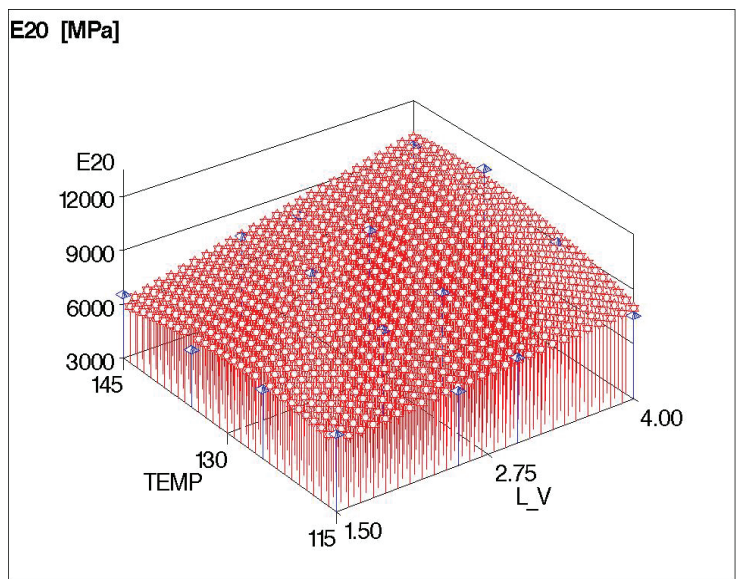

Fig. 4. The effect of the F-T wax amount (L_V) and the compaction temperature (TEMP) on the response surface for E20 [MPa] of AC $11 \mathrm{~S}$

Table 7

The estimation results of model (L_V and TEMP) parameters for characteristic E20 of AC $11 \mathrm{~S}$ and the estimation of their significance

\begin{tabular}{|l|c|c|c|c|}
\hline \multicolumn{1}{|c|}{ Parameter } & Estimation & Standard Error & Value of t & Pr $>|\mathbf{t}|$ \\
\hline Intercept & -44219 & 24288 & -1.82 & 0.0987 \\
\hline TEMP & 841.022628 & 369.126026 & 2.28 & 0.0459 \\
\hline L_V & -3402.679274 & 2099.740744 & -1.62 & 0.1362 \\
\hline TEMP*TEMP & -3.526458 & 1.411135 & -2.50 & 0.0315 \\
\hline L_V*TEMP & 34.853590 & 14.002378 & 2.49 & 0.0320 \\
\hline L_V*L_V & -20.027778 & 188.151299 & -0.11 & 0.9173 \\
\hline
\end{tabular}

The analysis of the results collated in Table 7 primarily indicates the significant impact of the temperature of compaction (TEMP) on the stiffness modulus of asphalt concrete AC $11 \mathrm{~S}$. No direct impact of the F-T synthetic wax (L_V) concentration on the stiffness modulus was observed in the developed model for the temperature of $20^{\circ} \mathrm{C}$ ( $p$-value $>0.05)$. However, as was the case with the stiffness modulus at the test temperature of $10^{\circ} \mathrm{C}$, the effect of interaction between those two parameters occurred. We can state that the interaction between the compaction temperature and the amount of the F-T synthetic wax has a highly significant effect on the E20 variation. The impact of significance of this fit element of the model (L_V*TEMP) was confirmed in the previous studies of stiffness modulus of asphalt concrete at the temperatures of $2^{\circ} \mathrm{C}$ and $10^{\circ} \mathrm{C}$. This fact can be related to different dynamics of bitumen and F-T wax viscosity variation during the investigations of the stiffness modulus of asphalt concrete AC 11 
S. As a result, the presence of the constant phase of F-T wax crystalline forms in combination with the process of asphalt concrete compaction acts jointly on its stiffness modulus at mean test temperatures (here: $2^{\circ} \mathrm{C}$ do $20^{\circ} \mathrm{C}$ ).

\section{Permanent deformation (Rts) of asphalt concrete at temperature of $50^{\circ} \mathrm{C}$}

The investigation of RTS [17] in relation to the amount of F-T wax (L_V) and the temperature of compaction (TEMP) of AC $11 \mathrm{~S}$ was based on a regression mathematical model. The domain of the experiment set the boundary conditions. The first step of the experiment was devoted to determining the adequacy of the model for describing the variation of RTS. In the second step, the significance of the parameters used in the developed regression response surface was estimated. The results of the analysis of the model fit for the RTS characteristic of asphalt concrete are presented in Tables 8 and 9 .

Table 8

Summary results of the model fit for RTS of AC $11 \mathrm{~S}$

\begin{tabular}{|l|c|}
\hline \multicolumn{2}{|c|}{ Response Surface for Variable RTS: RTS [\%] } \\
\hline RMSE & 0.289316 \\
\hline R-square & $83.48 \%$ \\
\hline Coefficient of Variation & 21.45567 \\
\hline
\end{tabular}

Table 9

Detailed results of polynomial degree fit for RTS of AC $11 \mathrm{~S}$

\begin{tabular}{|l|c|c|c|c|}
\hline \multicolumn{1}{|c|}{ Regression } & SS & MS & F & Pr $>$ F \\
\hline Linear & 2.323617 & 0.464723 & 6.488589 & 0.00614 \\
\hline Quadratic & 1.918112 & 0.959056 & 13.39059 & 0.001485 \\
\hline Crossproduct & 0.096695 & 0.048348 & 0.675042 & 0.53089 \\
\hline
\end{tabular}

The results of the analysis indicate that the square function model was the best fit for the RTS total change estimation. The value of the correlation coefficient was $\mathrm{R}^{2}=0.76$, which confirmed a high degree of fit of the model function with the deformation variation (RTS) in the entire domain determined by the amount of the F-T synthetic wax in $\mathrm{AC} 11 \mathrm{~S}$ and its temperature of compaction.

Figure 5 presents a graphical interpretation of the response surface for the RTS variable of $\mathrm{AC} 11 \mathrm{~S}$ at the temperature of $50{ }^{\circ} \mathrm{C}$ in relation to the amount of the F-T synthetic wax (L_V, \%) and the temperature of compaction (TEMP, $\left.{ }^{\circ} \mathrm{C}\right)$. The results of the estimation of the developed model parameters are presented in Table 10. 


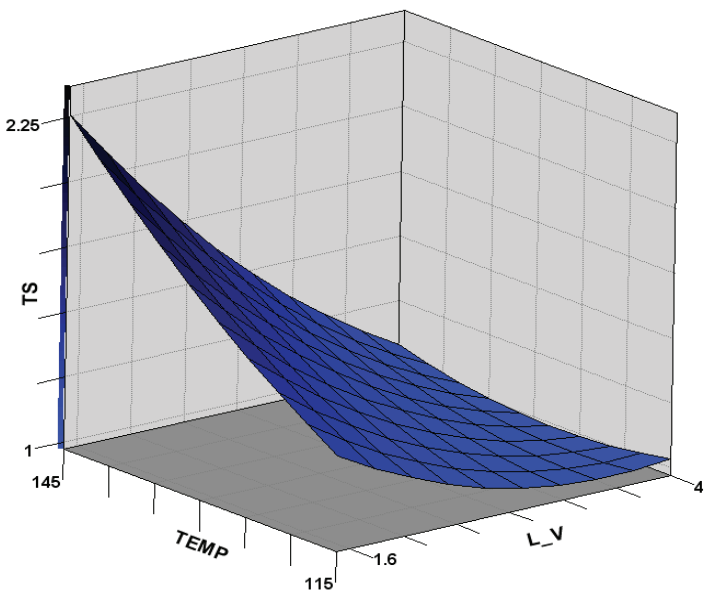

Fig. 5. The response surface for RTS [\%] of AC 11 S against the amount of F-T wax (L_V) in asphalt concrete and the temperature of compaction (TEMP)

Table 10

The results of the estimation of the parameters of model (L_V and TEMP) for RTS of asphalt concrete $\mathrm{AC} 11 \mathrm{~S}$ and estimation of their significance

\begin{tabular}{|l|c|c|c|c|}
\hline \multicolumn{1}{|c|}{ Parameter } & Estimation & Standard Error & Value of $\mathbf{t}$ & $\operatorname{Pr}>|\mathbf{t}|$ \\
\hline L_V & 1.335684 & 1.335684 & 18.64916 & 0.001517 \\
\hline TEMP & 0.582428 & 0.582428 & 8.132016 & 0.017201 \\
\hline L_V*L_V & 0.074939 & 0.074939 & 1.046318 & 0.330464 \\
\hline L_V*TEMP & 0.30881 & 0.30881 & 4.311683 & 0.06458 \\
\hline TEMP*TEMP & 0.021756 & 0.021756 & 0.303766 & 0.59363 \\
\hline
\end{tabular}

The analysis results show that there is a significant impact of both factors on the level of accumulated permanent deformation (RTS) of asphalt concrete. The effect of the temperature factor (TEMP) proved to be smaller than that of the F-T wax amount $(p$-value $=0.017)$. The significant influence of the non-linear parameter L_V in the model indicates that the F-T wax concentration in asphalt concrete, unlike the TEMP factor, has a dynamic effect. We can state that the amount of F-T wax in asphalt concrete 35/50 reduces non-linearly the level of total deformation of asphalt concrete and contributes to the increase in its resistance to this type of deformation [18]. Temperature affects the total deformation of asphalt concrete RTS proportionally to its increase. Increasing the temperature of compaction (TEMP) in interaction with an increased amount of modifier ( $\left.\mathrm{L}_{-} \mathrm{V}\right)$ at about $145^{\circ} \mathrm{C}$ causes a statistically significant 
increase in the susceptibility of asphalt concrete to permanent deformation. This effect is probably connected with improper compaction of asphalt concrete and reduction in friction level at the aggregate interfacial transition zone. It is thus necessary to reduce the compaction energy amount to obtain optimal level of void spaces for the asphalt concrete with non-modified bitumen compacted at temperatures recommended in WT-2/2010.

\section{Fatigue Life of ASPhalt CONCRETE, DETERMined USING THE IT-FT METHOD}

The evaluation of AC $11 \mathrm{~S}$ asphalt concrete fatigue process using the IT-FL method supplements the investigation of the effect of F-T wax on the deformation of asphalt concrete. In the light of regulations currently in force $[10,11]$ no fatigue criteria are available for surface courses of bitumen pavements. As the properly produced surface course with retained interlayer bond is subjected to compressive stresses, its fatigue life should tend to infinity. The range of tensile stresses occurs in the binder course at the depth from 8 to $12 \mathrm{~cm}[12]$.

To evaluate how the amount of F-T wax affects the fatigue life of the investigated asphalt concrete mixture, the controlled stress mode was employed in accordance with PN-EN 12697-24, Annex E [13] in the indirect tensile fatigue tests (IT-FT). The significant element of the investigation was introducing such a stress that will induce strain amplitude higher than $50 \mu \varepsilon$. In this range of compressive stress, fast cracking initiation in asphalt concrete can be expected $[14,15,16]$. The compressive stress used in the tests was $700 \mathrm{kPa}$. The tests ended when the asphalt concrete specimens shifted vertically by $5 \mathrm{~mm}$ or its stiffness modulus dropped by $50 \%$ after 30,000 loading cycles at a frequency of $1 \mathrm{~Hz}$.

The results of the analysis indicate a very close level of tests errors. The highest error level was recorded for asphalt concrete AC $11 \mathrm{~S}$ compacted at the low temperature of $115^{\circ} \mathrm{C}$ and when the amount of F-T wax was the smallest, i.e., $1.5 \%$. The dispersion of the results is related to high bitumen stiffness and the differentiation in the number of voids in the asphalt concrete. For all but one of the specimens there were no outliners at the variation coefficient of up to $20 \%$. The asphalt concrete at the compaction temperature of $115^{\circ} \mathrm{C}$ and F-T wax content of $1.5 \%$ had the stiffness modulus drop below 50\%, between 1900th and 2200th loading cycle. In the remaining cases the asphalt concrete had the stiffness modulus drop below 50\% after 30,000th loading cycle.

To visualise the course of changes in the stiffness modulus of AC $11 \mathrm{~S}$ in terms of the fatigue life for strains higher than $50 \mu \varepsilon$, the results of representative individual spectra are shown in Figure 6.

On the basis of data in Figure 6 we can state that low temperature of asphalt concrete compaction in interaction with small amount of F-T wax affected the compaction quality. In that case the initiation of cracking progresses the most quickly. The compar- 
ison of asphalt concrete compacted at $145^{\circ} \mathrm{C}$ and $1.5 \%$ content of F-T wax with that compacted at $125^{\circ} \mathrm{C}$ and $2.5 \%$ content of the modifier shows comparable results for the stiffness modulus drop. This confirms the fact that optimisation for bitumen $35 / 50$ with an addition of $2.5 \%$ of $\mathrm{F}-\mathrm{T}$ synthetic wax helps to reduce the compaction temperature by $25^{\circ} \mathrm{C}$ compared to conventional asphalt concrete. In addition, at the comparable fatigue life, higher resistance to permanent deformation was achieved for $\mathrm{AC} 11 \mathrm{~S}$ with F-T wax modified bitumen than for non-modified bitumen compacted in accordance with the relevant standard.

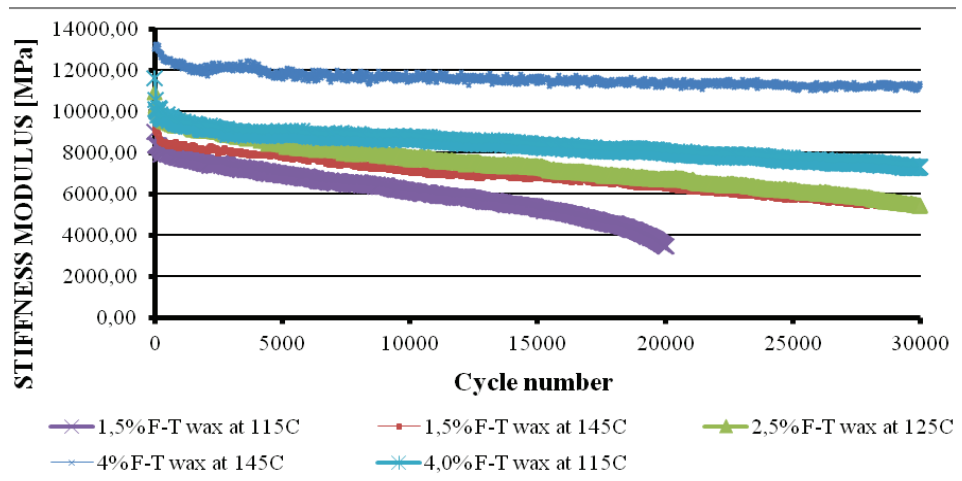

Fig. 6. Influence of F-T wax on the change in stiffness modulus of AC $11 \mathrm{~S}$ under cyclic loading

The influence of F-T wax and the temperature of compaction on the global evaluation of mean results of AC $11 \mathrm{~S}$ stiffness modulus testing using the IT-FT method as well as the test error assay are presented in Figure 7.

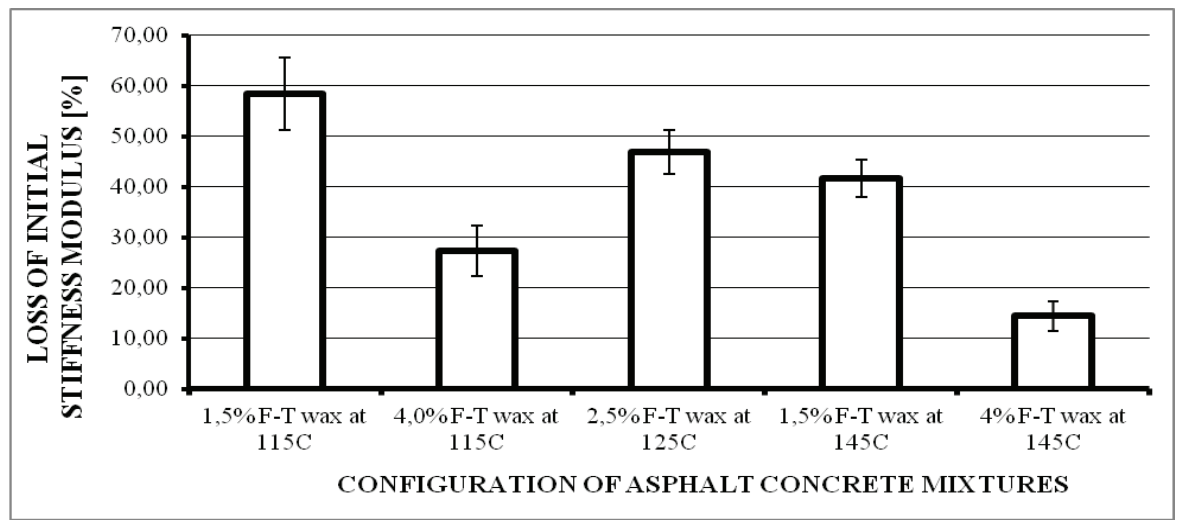

Fig. 7. Amount of F-T synthetic wax and temperature of compaction versus stiffness modulus of AC $11 \mathrm{~S}$ under cyclic load (ITFT) 
The results of analysis indicate that the dynamics of fatigue cracking initiation in AC $11 \mathrm{~S}$ asphalt concrete is significantly affected by the amount of F-T synthetic wax, the increase in which reduces the drop in the stiffness modulus value. Therefore, for the same loads lower strain values will be obtained and the cracking initiation dynamics will be reduced. In any case, an increase in F-T wax concentration from $1.5 \%$ to $4 \%$ caused the drop in stiffness of AC $11 \mathrm{~S}$ of about $50 \%$. This change in the stiffness modulus of the asphalt concrete was obtained when the temperature of compaction was $145^{\circ} \mathrm{C}$ and the modifier content was $4.0 \%$. A slight reduction in the stiffness modulus indicates a higher resistance of $\mathrm{AC} 11 \mathrm{~S}$ asphalt concrete to fatigue cracking in the range of up to 30,000 loading cycles may be connected with the character of over-densification of asphalt concrete and the low content of voids. However, in the case of the resistance to permanent deformation under conditions specified above, the asphalt concrete becomes highly susceptible to cyclic loading effect in the rutting tests. Thus the best solution, in relation to the reference asphalt concrete, is the application of F-T synthetic wax in the amount of up to $2.5-3 \%$ at the lower compaction temperature of about $25^{\circ} \mathrm{C}$. In this case, an increase in $\mathrm{AC} 11 \mathrm{~S}$ resistance to permanent deformation may reach $40 \%$ compared with the reference asphalt concrete at the comparable level of resistance to cyclic loading effect in the range of up to 30,000 loading cycles.

\section{RESISTANCE OF ASPHALT CONCRETE TO RUTTING}

The result for the resistance to rutting was determined for two measurements with difference of not more than $8 \%$ for all the possible changes of factors. Thanks to low dispersion of factors, its evaluation in the form of a mathematical model was conducted for two replications. Another stage of the analysis was devoted to the process of finding the model that would fit. The preliminary analysis of the model adequacy for characteristic $\mathrm{WTS}_{\mathrm{AIR}}$ of asphalt concrete in relation to the investigated independent variables $\left(\mathrm{L}_{-} \mathrm{V}\right.$, TEMP) is presented in Table 11.

Table 11

Summarised statistics of the model fit for $\mathrm{WTS}_{\mathrm{AIR}}$ of AC $11 \mathrm{~S}$

\begin{tabular}{|c|c|}
\hline \multicolumn{2}{|c|}{ Response Surface for Variable $\mathrm{WTS}_{\mathrm{AIR}}: \mathrm{WTS}_{\mathrm{AIR}}[\mathrm{mm} / 1000$ cykli] } \\
\hline RMSE & 0.024 \\
\hline R-square & $82.97 \%$ \\
\hline Coefficient of Variation & 7.42399 \\
\hline
\end{tabular}

For this class type of experiment, the most rational, considering the number of degrees of freedom (number of combinations of independent variables), is the classical type I response surface. The linear model fit is characterised by the coefficient of de- 
termination $\mathrm{R}^{2}=0.83$. The value of "Lack of fit" parameter if greater than the critical value ( $\mathrm{p}$-value $=0.07)$, which indicates the significance of the model applied. Therefore the description of variation of WTS $_{\text {AIR }}$, depending on the amount of F-T wax F-T (L_V) and the temperature of compaction (TEMP) of AC $11 \mathrm{~S}$ indicates a very good fit of the model.

A graphical interpretation of the response surface of the variation of rut increment WTS $_{\text {AIR }}$ at the test temperature of $60^{\circ} \mathrm{C}$ related to the amount of F-T synthetic wax $\left(\mathrm{L} \_\mathrm{V}, \%\right)$ and the temperature of compaction $\left(\mathrm{TEMP},{ }^{\circ} \mathrm{C}\right)$ is presented in Figure 8 . The results of the model parameters estimation for $\mathrm{WTS}_{\mathrm{AIR}}$ are collated in Table12.

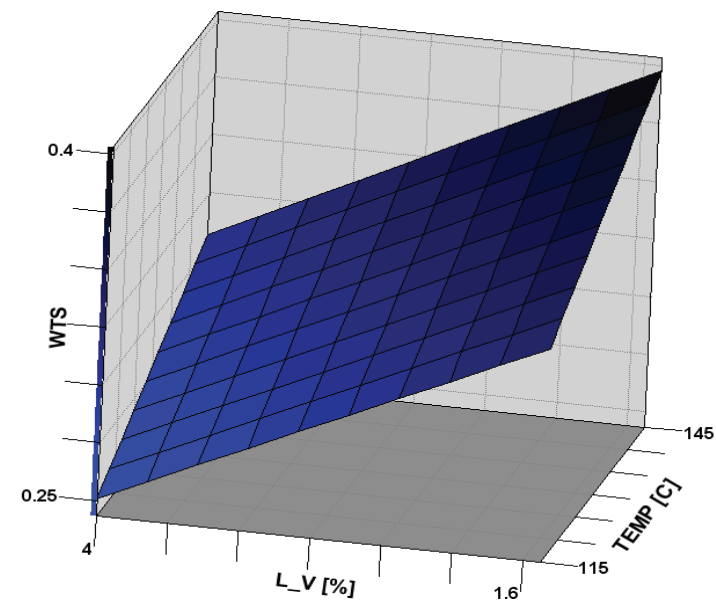

Fig. 8. Effect of the F-T wax amount (L_V) and the temperature of compaction (TEMP) on the response surface for $\mathrm{WTS}_{\mathrm{AIR}}[\mathrm{mm} / 1000$ cycles $]$ of AC $11 \mathrm{~S}$

Table 12

Results of the model parameters estimation (L_V and TEMP) for $\mathrm{WTS}_{\mathrm{AIR}}$

\begin{tabular}{|l|c|c|c|c|}
\hline \multicolumn{1}{|c|}{ Parameter } & Estimation & Standard Error & Value of t & $\operatorname{Pr}>|\mathbf{t}|$ \\
\hline TEMP & 0.06375 & 0.016877 & 3.77726 & 0.00921 \\
\hline L_V & -0.09625 & 0.016877 & -5.70292 & 0.001257 \\
\hline L_V*TEMP & -0.00375 & 0.016877 & -0.22219 & 0.831535 \\
\hline
\end{tabular}

The analysis of the characteristics obtained indicates that factors, the amount of F-T wax and the range of the compaction temperature, had a significant effect on WT$\mathrm{S}_{\mathrm{AIR}}$ variable of AC $11 \mathrm{~S}$ asphalt concrete. The synergy effect proved to be statistically insignificant. The lack of interaction is connected with the transition of bitumen 35/50 
modified with F-T synthetic wax into the state close to the Newtonian liquid. The stiffness during the rutting test at $60^{\circ} \mathrm{C}$ was caused by the F-T wax crystals. The temperature of compaction affects the quality of the asphalt concrete, expressed as a viscosity level of the binder and the resistance of its compaction in the constant volume. The effect of compaction temperature of AC $11 \mathrm{~S}$ remains independent of the amount of the F-T synthetic wax that affects the level of WTS $_{\text {AIR }}$ parameter. Generally, the bitumen 35/50-crystalline phase of F-T wax ratio will determine the velocity of deformation and the progressing structural damage to the asphalt concrete. With high quality of the model fit, we can state that the effect of F-T wax affects constantly and proportionally the decrease in the level of velocity of accumulation of permanent strain of the asphalt concrete AC $11 \mathrm{~S}$ represented by $\mathrm{WTS}_{\mathrm{AIR}}$ parameter.

Another parameter that was evaluated to determine the resistance to deformation was the characteristic of the rut increment PRDAIR of the asphalt concrete according to recommendations in WT-2 2010 [11]. Two samples were assayed of each factor combination (L_V, TEMP) of the experiment domain, the results of which varied within $6 \%$. The fit estimation of the model is presented in Table 13.

Table 13

Summarised statistics of the model fit for $\mathrm{PRD}_{\mathrm{AIR}}$ of $\mathrm{AC} 11 \mathrm{~S}$

\begin{tabular}{|l|c|}
\hline \multicolumn{2}{|c|}{ Response Surface for Variable PRD: PRD [\%] } \\
\hline RMSE & 0.613 \\
\hline R-square & $98.17 \%$ \\
\hline Coefficient of Variation & 5.01 \\
\hline
\end{tabular}

For this class type of experiment, the most rational, like in the case of $\mathrm{WTS}_{\mathrm{AIR}}$, is the classical type I response surface. The linear model fit is characterised by the coefficient of determination $\mathrm{R}^{2}=0.98$. The value of "Lack of fit" parameter if greater than the critical value ( $p$-value $=0.387)$, which indicates the significance of the model applied. Therefore the description of variation of $\mathrm{WTS}_{\mathrm{AIR}}$, depending on the amount of F-T wax F-T (L_V) and the temperature of compaction (TEMP) of AC $11 \mathrm{~S}$ indicates a very good fit of the model applied.

A graphical interpretation of the response surface of the variation of rut depth PR$\mathrm{D}_{\mathrm{AIR}}$ at the test temperature of $60^{\circ} \mathrm{C}$ for asphalt concrete related to the amount of F-T synthetic wax (L_V, \%) and the temperature of compaction (TEMP, $\left.{ }^{\circ} \mathrm{C}\right)$ is presented in Figure 9. The results of the developed model parameters estimation are collated in Table 14.

The result of the analysis indicate a significant impact of both factors, the amount of FT wax and he compaction temperature of $A C 11 \mathrm{~S}$, on the rut depth PRD $_{\text {AIR }}$ increment expressed in percentage. Alongside the statistically significant impact of the 
factors investigated (L_V, TEMP) on asphalt concrete, the synergy effect occurred for the independent variables discussed. This indicates that the rut depth is affected by the amount of the F-T wax present in the bitumen 35/50 in combination with the quality of compaction of $\mathrm{AC} 11 \mathrm{~S}$ determined by the compaction temperature. Hence, ensuring the proper process of asphalt concrete compaction can reduce deformation of the asphalt concrete. Also, the deformation depth increment, as in the case of RTS (simplify triaxial compression) [17], shows a strong relation to the asphalt concrete compaction temperature. When the bitumen viscosity level is too low at the compression phase at the constant compaction energy, the content of voids is insufficient. The lack of aggregate interlocking in the asphalt concrete produces an adverse effect. In such a case an excessive amount of F-T wax in combination with high temperature makes the asphalt concrete "flow." The course of the response surface confirms that fact. For the given value of F-T wax, the deformation of asphalt concrete expressed by $\mathrm{PRD}_{\mathrm{AIR}}$ increases with the compaction temperature increase.

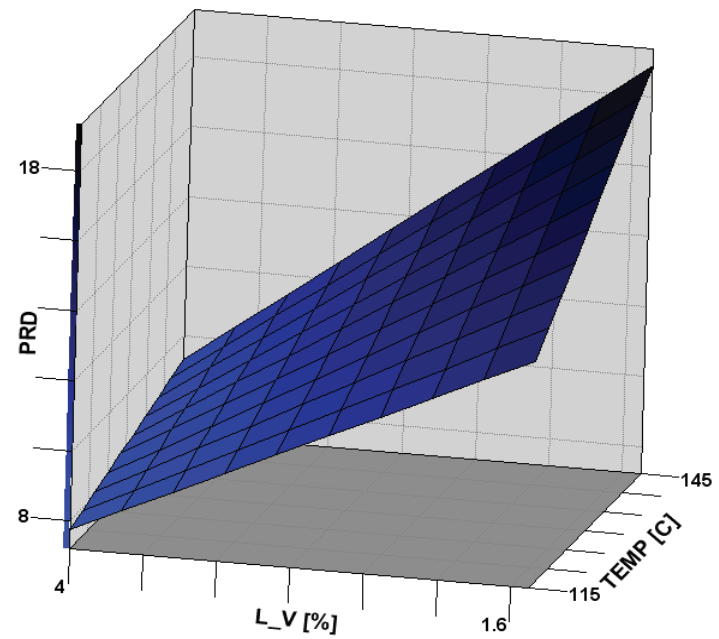

Fig. 9. Effect of the F-T wax amount (L_V) and the temperature of compaction (TEMP) on the response surface for $\mathrm{PRD}_{\mathrm{AIR}}[\%]$ of $\mathrm{AC} 11 \mathrm{~S}$

Table 14

Results of the parameter estimation of (L_V an TEMP) model for PRDAIR

\begin{tabular}{|l|c|c|c|c|}
\hline \multicolumn{1}{|c|}{ Parameter } & Estimation & Standard Error & Value of $\mathbf{t}$ & $\operatorname{Pr}>|\mathbf{t}|$ \\
\hline TEMP & 3.525 & 0.433229 & 8.136572 & 0.0002 \\
\hline L_V & -8.625 & 0.433229 & -19.9086 & 0.0001 \\
\hline L_V*TEMP & -2.125 & 0.433229 & -4.90503 & 0.0027 \\
\hline
\end{tabular}


On the basis of the properties of AC $11 \mathrm{~S}$ that are connected with the resistance to permanent deformation, an attempt was made to find predictions for parameters RTS

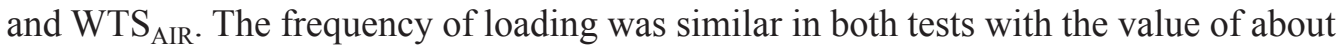
$1.5 \mathrm{~Hz}$. The difference between the test temperature in both tests was $10^{\circ} \mathrm{C}$. Both tests were conducted with the side restraint of the asphalt concrete specimens. A regression analysis was used to evaluate the relationship between the parameters.

The noise connected with the outliers was eliminated by eliminating measurements that contained large errors, owing to a high sensitivity of the coefficient of determination $\mathrm{R}^{2}$. Large errors may cause disturbance in the whole process of finding the trend line model. To carry out an analysis of correlation, all the tests results were used and the results for WTSAIR and RTS were grouped by the compaction temperature level and F-T wax content in the asphalt concrete. For that purpose, t-studentised residuals were used. The test values higher than 2 have to be treated as those that contribute to biased estimation of regression parameters and which destabilise the correlation variance. The distributions of residuals of the explanatory variable $\mathrm{WTS}_{\mathrm{AIR}}$ are presented in Figure 10.

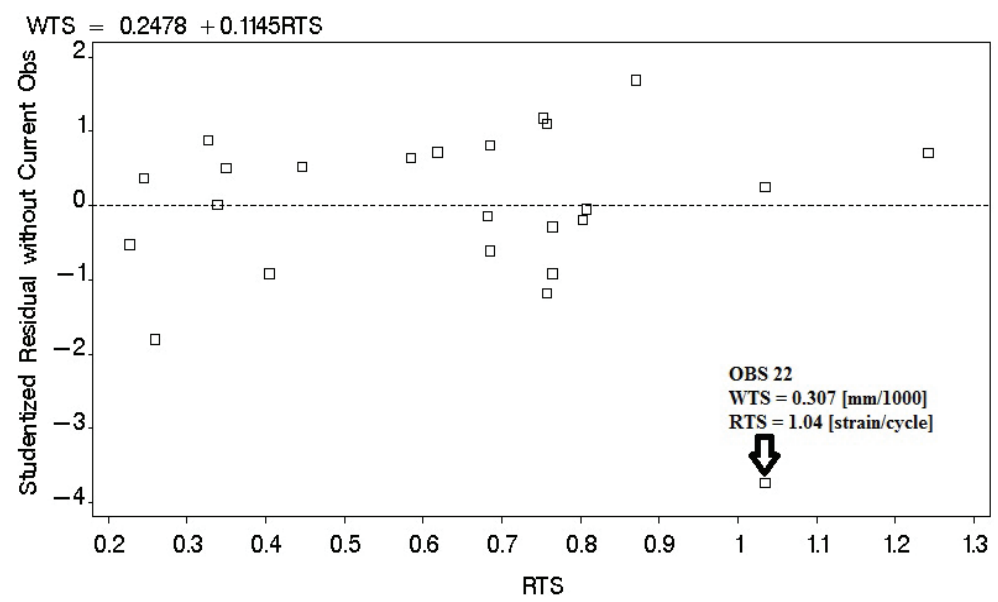

Fig. 10. Values of t-studentised residuals of the explanatory variable $\left(\mathrm{WTS}_{\mathrm{AIR}}\right)$ of AC $11 \mathrm{~S}$

It must be emphasized that observation 22 lies far from the mean value level. The value of the t-studentised residual is greater than 2 . Therefore, further in the analysis this observation was eliminated. The ultimate form of the model is shown in Figure 11.

Analysis results presented in Figure 11 indicate that there is a close relationship as for the measurement of the velocity of total irreversible deformation increment in relation to parameters WTS $_{\text {AIR }}$ and RTS of AC $11 \mathrm{~S}$. The correlation strength is at a very 
high level reaching $81 \%$. Owing to information about the AC $11 \mathrm{~S}$ deformation velocity, obtained from the dynamic creep tests with the side restraint, it is possible to predict the susceptibility of the asphalt concrete in rutting tests much faster (the duration of the dynamic creep tests with the side restraint was 2 hours).

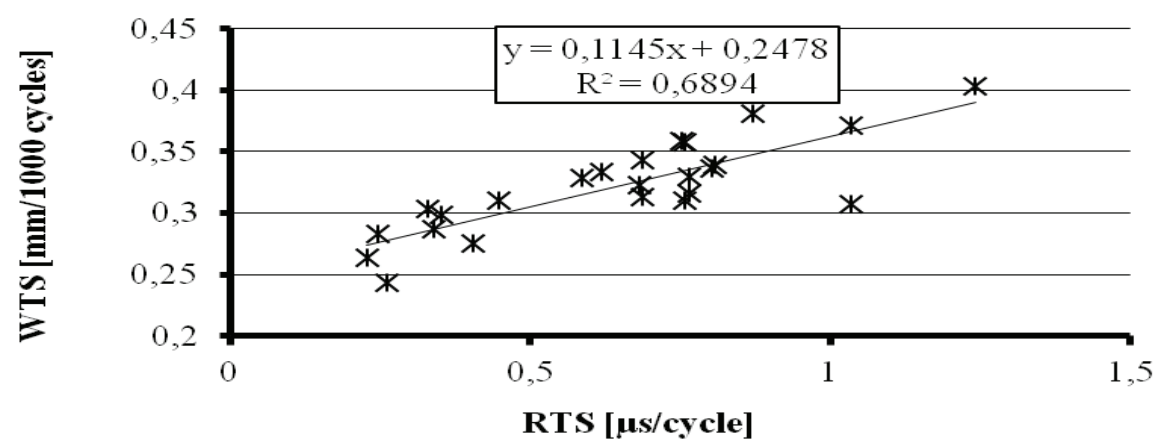

Fig. 11. Correlation of the velocity of deformation according to the rutting test for $\mathrm{WTS}_{\mathrm{AIR}}$ and according to the dynamic creep tests with a side restraint for RTS of AC $11 \mathrm{~S}$

\section{Conclusions}

The investigations of the effect of F-T synthetic wax on the resistance of AC $11 \mathrm{~S}$ asphalt concrete helped formulate the following conclusions:

- the structuring property of F-T wax present in the bitumen 35/50 significantly contributes to the reduction in the level of AC $11 \mathrm{~S}$ strain in the triaxial compression tests (RTS) and rutting tests (WTSAIR, PRDAIR), increasing its resistance to permanent deformation;

- the velocity of stiffness modulus drop, determined during the estimation of the fatigue life according to the ITFT method, for the asphalt concrete with $2.5 \%$ of F-T wax compacted at the temperature of $125^{\circ} \mathrm{C}$, is comparable with the characteristics of the reference asphalt concrete compacted at $145^{\circ} \mathrm{C}$;

- the use of bitumen with an addition of $2.5 \% \mathrm{~F}-\mathrm{T}$ wax in the asphalt concrete $\mathrm{AC} 11$ $\mathrm{S}$ at the compaction temperature of $125^{\circ} \mathrm{C}$ leads to the reduction in the level of WTSAIR parameter that characterizes the velocity of permanent deformation by $40 \%$ when compared with conventional asphalt concrete, which ensures higher resistance of bitumen pavements to rutting. 


\section{REFERENCES}

1. J. Judycki, B. Dołżycki, Analysis of permanent deformation of asphalt pavement on the basis of field and laboratory testing of permanent deformations (in Polish), VIII Konferencja Naukowa Komitetu Inżynierii Lądowej i Wodnej PAN i Komitetu Nauki PZITB, Krynica 2002, Inżynieria komunikacyjna, s. 201-208.

2. J. Piłat, P. Radziszewski, Road materials technology (in Polish). WKŁ, 2009, 509 s.

3. B. Stefańczyk, P. Mieczkowski, Hot mix asphalt - performance and research (in Polish). WKŁ. Warszawa. 2008.

4. M. Kilas M, A. Vaitkus., M. Paliukaite, Warm Mix Asphaltes Research, Analysis and Evaluation, The $10^{\text {th }}$ International Conference "Modern Building Materials, Structures and Techniques", Vilnius, 2010, pp. 149-155,

5. T. Butz, Warm Mix Asphalt - Technologies, research and Experiences, Sasol Wax GmbH

6. H. Silva H, J.Oliviera, J.Peralta, S. Zoorob, Optimization of warm mix asphalts using different blends of binders and synthetic paraffin wax contents, Construction and Building Materials, 24, pp. 16211631,2010

7. Z. Piasta Z., A. Lenarcik, Methods of statistical multi-criteria optimization, [in] A.Brandt (ed.), Optimization Methods for Material Design of Cement-based Composites, E\&FN Spon, London, New York, 45-59, 1998

8. J. Judycki, M. Stienss M, Bituminous mixtures tests coated at low temperature (in Polish), Raport końcowy GDDKiA, 2011

9. M. Duriez, Nouveau traité de materiaux de construction, Bd III,1961.

10. B. Stefańczyk, praca zbiorowa, General Building Engineering (in Polish). Tom I, Arkady, 2005

11. PN EN 13108-1 Road bituminous mixtures (in Polish).

12. WT-2 Technical requirements (in Polish), GDDKiA 2010

13. J. Judycki, Fatigue o asphalt mixes, OULU 1991.

14. S. Lawrence, Effect of Bitumen Flow Improvers on the Compatibility and Stability of Hot Rolled Asphalts, Diplomarbeit an der HAW Hochschule fur angewandte Wissenschaften, Hamburg 2001.

15. M. Zaky, N.H. Mohamed, Comparative study on separation and characterization of high melting point macro- and micro-crystalline waxes, Journal of the Taiwan Institute of Chemical Engineers, 41, 2010.

16. M. Iwański, G. Mazurek, Water and Frost Resistance of Asphalt Concrete Produced in the Warm Technology - 10th International Conference Modern Building Materials, Structures and Techniques in Vilnius, 19-21 May 2010, pp. 200-206.

17. PN EN 12697-25:2005 Bituminous mixtures. Test methods for hot mix asphalt - Part 25: Cyclic compression test (in Polish).

18. W. Grabowski, M. Słowik and M. S. Kuczma, Modelling the creep experimental results for a polymer modified bitumen (in Polish), Archives of Civil Engineering L, 1, 2004, 151-160

19. S. Gopinath, A. Ramachandra murthy, D. Ramya, Nagesh R. Iyer, Optimised mix design for normal strength and high performance concrete using particle packing method, Archives of Civil Engineering, LVII, 4, 2011, 357-371 